\title{
Grupo de Acolhimento: Cuidado ao Paciente e Familiares
}

\author{
Yamada, Midori Otake; Moret, Adriane Lima Mortari; Silva, Ariane Marta de Lima; \\ Rezende, Fernanda Pádua \\ Hospital de Reabilitação de Anomalias Craniofaciais - USP — midoriotake@yahoo.com.br
}

INTRODUÇÃO:A partir da Política Nacional de Humanização do Sistema Único de Saúde (SUS), o acolhimento tornou-se procedimento básico no tratamento do usuário, baseandose na escuta clínica, é um processo de relações humanas que deve ser realizado por todos os trabalhadores de saúde e em todos os setores de atendimento. o profissional deve ter uma postura que permita receber bem os usuários e escutar de forma qualificada e humanizada as suas demandas, solidarizando-se com o sofrimento. Este trabalho é referente a implementação do grupo de acolhimento de casos novos na rotina de atendimento de um serviço público de saúde brasileiro. Nesse sentido algumas indagações se fazem necessárias: Quem é o usuário? Qual sua queixa e expectativa? como se sente? Enfim, o grupo tem trazido benefícios aos usuários? e para a equipe? Estas e outras questões são pertinentes no desenvolvimento da rotina de trabalho. OBJETIVO:Refletir sobre o grupo de acolhimento de casos novos, descrevendo a população atendida, suas queixas e expectativas. MÉTODO:O grupo é realizado duas vezes na semana, com a duração de quarenta minutos e com a participação de três casos novos, nas várias faixas etárias e seus acompanhantes. a coordenação é da equipe interdisciplinar, nas áreas da psicologia, fonoaudiologia e serviço social. Durante dois meses do ano de 2013 , observouse as reuniões e utilizou-se de anotações como forma de coleta das informações trazidas pelos usuários. RESULTADOS: Os usuários que procuraram o atendimento foram pais de crianças com idades em torno de seis meses a quatro anos e adultos com acompanhantes. Relataram um pouco de suas histórias e das preocupações e angústias em relação à deficiência auditiva. As queixas apresentadas foram sobre suspeitas da deficiência auditiva, dúvidas quanto ao diagnóstico, não ter tratamento na cidade de origem e sobre possibilidades de tratamento. As expectativas se mostraram pouco realistas, realistas e irreais; no caso da criança, refletindo o desejo dos pais e nos adultos, os seus próprios desejos. Tem sido observado que o grupo de acolhimento propicia a troca de experiências entre os usuários, a expressão de pensamentos e sentimentos, o esclarecimento de dúvidas e a integração com a equipe. Este contato inicial tem favorecido o conhecimento do caso pela equipe, possibilitando identificar possíveis riscos e barreiras, direcionando o encaminhamento dos casos, o que reflete na otimização do tempo do paciente e da equipe e na continuidade dos atendimentos. CONCLUSÃO: A partir dessa experiência com o grupo de acolhimento de casos novos, recentemente iniciado, acreditamos que esse se constitui em um dos caminhos para a melhoria da qualidade da atenção ao cuidado do paciente e familiares, inclusive para promover a prática da interdisciplinaridade, numa concepção de trabalho humanizado.

Yamada, Midori Otake; Moret, Adriane Lima Mortari; Silva, Ariane Marta de Lima; Rezende, Fernanda Pádua. Grupo de Acolhimento: Cuidado ao Paciente e Familiares. In: Anais do Congresso Internacional de Humanidades \& Humanização em Saúde [= Blucher Medical Proceedings, num.2, vol.1]. São Paulo: Editora Blucher, 2014. ISSN 2357-7282

DOI 10.5151/medpro-cihhs-10248 